\title{
Utilitarianism and Animal Cruelty: Further Doubts
}

\author{
Ben Davies
}

\begin{abstract}
Utilitarianism has an apparent pedigree when it comes to animal welfare. It supports the view that animal welfare matters just as much as human welfare. And many utilitarians support and oppose various practices in line with more mainstream concern over animal welfare, such as that we should not kill animals for food or other uses, and that we ought not to torture animals for fun. This relationship has come under tension from many directions. The aim of this article is to add further considerations in support of that tension. I suggest three ways in which utilitarianism comes significantly apart from mainstream concerns with animal welfare. First, utilitarianism opposes animal cruelty only when it offers an inefficient ratio of pleasure to pain; while this may be true of eating animal products, it is not obviously true of other abuses. Second, utilitarianism faces a familiar problem of the inefficacy of individual decisions; I consider a common response to this worry, and offer further concerns. Finally, the common utilitarian argument against animal cruelty ignores various pleasures that humans may get from the superior status that a structure supporting exploitation confers.
\end{abstract}

\section{Introduction}

There are various connections between utilitarianism ${ }^{1}$ and certain practices aimed at promoting the welfare of animals. Utilitarianism supports the view that non-human animal suffering is morally just as important as human suffering. ${ }^{2}$ And many utilitarians

\footnotetext{
${ }^{1}$ In what follows, unless otherwise specified 'utilitarianism' will mean hedonistic act utilitarianism, where what one morally ought to do is either whatever will bring about the greatest available balance of pleasure over pain, or whatever one could reasonably expect to bring this about.

2 Jeremy Bentham, An Introduction to the Principles of Morals and Legislation (Oxford: Clarendon Press, [1789] 1907), at C17, n122; John Stuart Mill, 'Whewell on Moral Philosophy', in The Collected Works of John Stuart Mill, edited by John M. Robson (London: Routledge and Kegan Paul, [1852] 1963-1991), Volume X, pp. 185-187; Henry Sidgwick, The Methods of Ethics, 7th edition (London: MacMillan, [1874] 1907), Book IV, Chapter I; Peter Singer, Animal Liberation, 2nd Edition (London: Cape, [1975] 1990); Peter Singer, Practical Ethics, 3rd Edition (Cambridge: Cambridge University Press, [1979] 2011).
} 
support particular moral commitments that line up with the commitments of advocates of animal rights and animal welfare who are not philosophers, the most obvious example being that we should not kill or exploit non-human animals for food, or exploit them in other ways for our pleasure. ${ }^{3}$ I will call the stance that we ought not, for utilitarian reasons, engage in these acts 'vegan-utilitarianism'.

We can contrast vegan-utilitarianism with veganism as it is typically practiced by non-philosophers. Of course, people practice veganism for a variety of reasons, and to differing degrees. But we may take the stance of the Vegan Society as at least one central kind of veganism. The Society quotes its 1979 Articles of Association as saying that veganism is 'a philosophy and way of living which seeks to exclude - as far as is possible and practicable - all forms of exploitation of, and cruelty to, animals for food, clothing or any other purpose'. Call this, for want of a better word, 'everyday veganism'.

This paper explores vegan-utilitarianism in some detail, and offers three reasons to think that it overlaps rather less with the concerns of everyday vegans than may initially appear to be the case. My conclusion is that supporters of animal welfare should not regard utilitarianism as a more plausible moral theory because it offers intuitively 'correct' answers on this issue. It is important to distinguish this from the outset from two alternative claims. First, I am not claiming that, until now, there have been no objections raised against a utilitarian approach from an animal welfare perspective; clearly, there have been criticisms from feminist care ethics ${ }^{4}$ and from rights-based perspectives. ${ }^{5}$ Other authors have suggested that a properly utilitarian approach might advocate practices that many supporters of animal welfare would condemn. As McMahan ${ }^{6}$ suggests, the aim of minimising non-human suffering seems to imply that, in the right circumstances, we ought to 'arrange the gradual extinction of carnivorous species, replacing them with new herbivorous ones', since a significant amount of animal suffering is caused by other animals in the wild; although as McMahan acknowledges, our current state of understanding renders this move unwise in the extreme. This argument is also made by Singer. ${ }^{7}$ Davis questions whether a strict refusal to eat animal products, or even animals themselves, is the best way to reduce overall suffering. ${ }^{8}$ In this sense, this paper can be

3 E.g., Singer, Animal Liberation; Alastair Norcross, 'Puppies, Pigs and People', Philosophical Perspectives 18:1 (2004), pp. 229-245; Gaverick Matheney, 'Expected Utility, Contributory Causation, and Vegetarianism', Journal of Applied Philosophy 19:3 (2002), pp. 293-297; Gaverick Matheney, 'Least Harm: A Defense of Vegetarianism from Steven Davis's Omnivorous Proposal', Journal of Agricultural and Environmental Ethics 16:5 (2003), pp. 505-511; Gaverick Matheney, 'Utilitarianism and Animals', in In Defense of Animals: The Second Wave, edited by Peter Singer (Oxford: Blackwell, 2005), pp. 13-26.

${ }^{4}$ E.g. Josephine Donovan, 'Animal Rights and Feminist Theory', Signs 15:2 (1990), pp. 350-375.

5 E.g. Tom Regan, 'Utilitarianism, Vegetarianism, and Animal Rights', Philosophy \& Public Affairs 9:4 (1980), pp. 305-324; Tom Regan, The Case for Animal Rights, 2nd Edition (California: University of California Press, [1983] 2004), pp. 195-231; Sue Donaldson and Will Kymlicka, Zoopolis: A Political Theory of Animal Rights (Oxford: Oxford University Press, 2011).

6 Jeff McMahan, 'The Meat Eaters', The New York Times (September 19th, 2010). Online at: http:/ /opinionator.blogs.nytimes.com/2010/09/19/the-meat-eaters (accessed 2016-05-25).

7 Singer, Animal Liberation, p. 227

8 Steven Davis, 'The Least Harm Principle may Require that Humans Consume a Diet Containing Large Herbivores, Not a Vegan Diet', Journal of Agricultural and Environmental Ethics 16:4 (2003), pp. 387-394. Gaverick Matheney offers a response in 'Least Harm: A Defense of Vegetarianism from 
seen as offering further reasons to suspect that the connection between utilitarianism and everyday veganism is more fragile than it seems. It will not shock anyone with any knowledge of moral philosophy to hear that utilitarianism will sometimes advocate actions that different moral views - such as rights-based views - will condemn. My aim is not to reveal something surprising about utilitarianism itself, but to explore some underdiscussed implications of utilitarian commitments to suggest that, at a practical level, there is rather less agreement between vegan-utilitarians and other vegans than has typically been supposed.

Second, I am not going to argue that utilitarianism has no scope for condemning abuses of animals; even given the objections I will raise, I think that utilitarians should clearly condemn many current practices in industrial farming, for instance.

For the purposes of this paper, I take veganism in a broad sense, as the abstention both from food products produced by animals, including the animals themselves, and from other ways of using animals primarily for our own gain, to their cost; this includes using animals as a form of entertainment. Of course, it may be that some animal products do not require causing animals pain, or killing economically useless male offspring; ${ }^{9}$ but I will ignore such cases. Readers should assume that I am discussing only cases where the use of animals involves causing harm, including death. Some reasons for doing this seem to fit fairly well with a utilitarian outlook, where practices cause animals physical and emotional suffering, and deprive them of pleasures they would otherwise have had. Other reasons, such as a concern with exploitation in and of itself, or a focus on rights violations, fit less obviously. But it does seem to be the case that many vegans are motivated largely by the idea of reducing suffering, and almost all are motivated by it to some degree. Moreover, even if it is for different reasons, it seems as though veganutilitarians and their everyday counterparts will end up advocating similar actions and abstentions in a great many cases. As I will argue, however, the overlap between these two stances is rather slimmer than it might first appear.

Vegan-utilitarians do not always offer exclusively utilitarian arguments; Singer, ${ }^{10}$ for instance, appeals to the idea of 'marginal cases', such as humans who lack the complex cognitive capacities that are usually taken to distinguish humans from other animals. But it seems clear that as utilitarians their position is ultimately motivated by utilitarianism, and that they think utilitarian arguments should carry the day even if they are prepared to appeal to other kinds of arguments as an ecumenical exercise. Regan quotes Singer as saying that

Steven Davis's Omnivorous Proposal', Journal of Agricultural and Environmental Ethics 16:5 (2003), pp. 505-511.

9 E.g., see Heather Saul, 'Hatched, Discarded and Gassed: What Happens to Male Chicks in the UK', The Independent (March 5th, 2015). Online at: http://www.independent.co.uk/life-style/foodand-drink/hatched-discarded-gassed-what-happens-to-male-chicks-in-the-uk-10088509.html (accessed 2016-05-25).

10 Singer, Practical Ethics, p. 66. Given my explicit definition of utilitarianism in note 1 as 'hedonistic act utilitarianism', it is worth acknowledging that Singer's view in Practical Ethics is in fact a form of preference utilitarianism. However, Singer has more recently abandoned the preference view for its hedonistic counterpart; e.g., see Katarzyna de Lazari-Radek and Peter Singer, The Point of View of the Universe: Sidgwick and Contemporary Ethics (Oxford: Oxford University Press, 2014), pp. 240-283. 
I think that the only right I ever attribute to animals is the 'right' to equal consideration of interests, and anything that is expressed by talking of such a right could equally well be expressed by the assertion that animals' interests ought to be given equal consideration with the like interests of humans[,]11

which he takes to be a utilitarian perspective.

The next three sections respectively consider three tensions between utilitarian and everyday veganism. One of these tensions has been well explored, although I aim to offer some novel considerations; the other two, so far as I am aware, have not.

First, I suggest that a focus on the eating of animals may mislead us about the level of agreement between utilitarians and other animal welfare stances. This is because utilitarianism opposes these practices for the only reason it can oppose any practice: because they lead to an inefficient trade off of pleasure and pain. When confronted with more efficient practices, utilitarianism offers us no reason to oppose them.

Second, it is a familiar problem for vegan-utilitarianism that although it sees the suffering caused by producing meat as outweighing the pleasure gained from meateating, it must confront what we may call the efficacy problem: in a large capitalist economy, one person's eating habits make no difference to the production of meat. Alastair Norcross offers a probabilistic response to this problem, ${ }^{12}$ and I suggest some problems with it. I then consider the more plausible response that utilitarians should instead endorse much more active responses than a mere refusal to eat meat.

This, however, points to the third problem. I adapt an argument from Coleman, who criticises the assumption that utilitarianism obviously opposes racialized slavery, to suggest that there may be other forms of pain and pleasure involved in the use of animal products, and that the balance of pain and pleasure does not obviously come out in favour of veganism, or indeed of any particularly radical stance on animal rights. ${ }^{13} \mathrm{I}$ should note from the outset that my analogy stretches only so far as the form of Eoleman's argument; I do not attempt to make any analogy between the conditions suffered by slaves in the particular historical instances that Coleman discusses, and the condition of animals that are exploited by humans.

\section{The Efficiency Problem}

A central utilitarian argument against using animal products is that the suffering and death of individual animals clearly outweighs the pleasure achieved by those who eat or

11 Peter Singer, The Fable of the Fox and the Unliberated Animals. Ethics 88: 2 (1978), pp. 119-125, at p. 122; quoted in Tom Regan, 'Utilitarianism, Vegetarianism and Animal Rights', p. 307.

12 Norcross, 'Puppies, Pigs and People'.

${ }^{13}$ Nathaniel Adam Tobias Eoleman, 'What is wrong with [R.M. Hare's argument against] slavery', available

https://www.academia.edu/2761414/What_is_wrong_with_R._M._Hares_arguments_against_sla very (Unpublished). Eoleman intentionally crosses out his name due to its historical connections with the slavery of his ancestors. See Gender and Philosophy: The Blog, How Philosophy Was "Whitewashed", interview with Dr Nathaniel Coleman (August 24 $4^{\text {th }}$ 2015). Available at http://www.ucl.ac.uk/european-institute/press/2014-15/philosophy-whitewash (available 201610-24). 
use the products. At least for citizens of wealthy countries, who can get nourishment without the use of animal products, this seems largely true. What is particularly compelling about this argument from a utilitarian perspective is that an individual animal can produce only so much meat, for instance, and that meat can only produce a limited amount of pleasure amongst those who eat it, because once it is gone it is gone. As Singer puts it:

In considering the ethics of the use of animal flesh for human food in industrialized societies, we are considering a situation in which a relatively minor human interest must be balanced against the lives and welfare of the animals involved ${ }^{14}$

But the fact that the pleasure one gains from eating meat is a 'minor interest' is not itself a utilitarian argument. This is for two reasons. First, Regan points out that there may be many other interests involved in meat-eating, such as people's livelihoods, that are less clearly characterised as minor compared with the pleasures involved in eating meat; ${ }^{15}$ I address this idea in more detail in the fourth section. But it is also worth noting that the claim that the interests involved in meat-eating are minor only supports the utilitarian argument that we should avoid eating meat if we add the further premise that the lives and welfare of each animal must be balanced against very few instances of this minor interest.

When it comes to meat eating, and most other consumed animal products, this premise is likely to be true. Food can only feed so many people, or the same person so many times, and it goes off if it is not used. But utilitarians are not welcome to help themselves to that latter premise in all instances of animal killing or ill-treatment. Consider a different, but also common, use of animals that requires killing them: leather. Leather, if well treated, lasts considerably longer than food. A pair of leather shoes might provide a significant amount of pleasure to a single person if he wears them every day. Once he is done with them, that needn't be the end of the pleasure; he might pass them onto a relative or friend, or simply donate them to charity, providing someone else with the opportunity to get some use out of them. And when they are no longer any good as shoes, the leather itself can be recycled for a variety of other uses. I do not know whether all these multiple uses would outweigh the suffering caused to the animal that was killed for its skin. But it at least seems far less obvious than the equivalent question about that animal's meat.

It might be possible, given certain science fictional technologies, to sever the connection between animal suffering and pleasure inefficiency even in the case of eating animal products. We might imagine a machine of the kind dreamt up by Philip K. Dick, where 'empathy-boxes' link the experiences of one individual to many others: ${ }^{16}$ if the pleasure one person experiences from eating an animal could be simultaneously felt by many others, a great deal more pleasure would be produced for the same amount of pain. But the case is perhaps more persuasively felt by sticking to realistic examples, such as the leather shoes.

14 Singer, Practical Ethics, p. 54.

15 Regan, 'Utilitarianism, Vegetarianism and Animal Rights', pp. 310-312.

16 Philip K. Dick, Do Androids Dream of Electric Sheep? (Orion Books: London, [1968] 1999). 
Of course, a utilitarian will reasonably object at this point that the relevant question is not simply whether the use of leather produces more pleasure than pain, but whether it produces a better balance than the alternatives. And nowadays, there are plenty of vegan alternatives to leather shoes, including ones that are sufficiently smart to pass muster in the most formal environments. Given such alternatives, there is no excuse to buy leather. One potential issue with this response, is the assumption that alternative products provide all the pleasures of leather shoes. As I suggest in the fourth section, there may be certain psychological benefits from using animal products that cannot be replicated by vegan products because it is the fact that it is an animal product that causes the pleasure. Nonetheless, this response clearly reduces the likelihood that using leather will come out as the best option overall under a utilitarian framework.

There are, however, more difficult cases. Most everyday vegans are opposed to forms of entertainment that involve cruelty to animals, such as horse racing, bullfighting and the use of animals in circuses. But it should be clear that whereas a single animal can only serve as food for a small number of people (science fiction cases notwithstanding), a single animal involved in a bull fight, for instance, can entertain a much larger group. Unlike the pleasures involved in eating, the pleasure of entertainment is in principle what McAfee and Brynjolfsson refer to as 'non-rival': its enjoyment by one person does not necessarily impede its equal enjoyment by others. ${ }^{17}$ Until relatively recently, such entertainments might have been non-rival in principle but not in practice, since practices such as bull fighting require venues, which have limited capacities. But we have for some while had the capacity to offer access to all forms of entertainment to many people at once via communications technologies. In principle, entertainments involving cruelty to animals could entertain millions or even billions. If the spectacle involves only a few animals, it becomes increasingly unlikely that the level of pain caused will outweigh the total, non-rival pleasure spread across all spectators.

What about the possibility that there are direct substitutes that clearly provide a better balance of pleasure and pain, as seems to be the case for food and, perhaps, leather? We might suggest that someone who wants to go to watch the bull fight should instead watch a football game, or go to the ballet; both of these are entertaining, and neither requires animal cruelty. But this is simply not how entertainment works. Certainly, someone who finds the ballet just as entertaining as the bull fight may do better in a moral sense not to watch the fight. But why should we think that fans of bull fighting will find other activities just as entertaining? It might be the kind and intensity of pleasure available from watching a bullfight is available only from a bull fight, at least for many spectators.

One response to this is that alternative forms of entertainment do not need to be as entertaining as a bull fight to triumph in a utilitarian calculus, since their lack of involvement with animal cruelty means that they are at a significant advantage in the balance of pleasure over pain. What we should each do as ethical consumers is to find another source of entertainment that, while less entertaining than bull fighting, provides the best overall balance of pleasure and pain.

However, as the third section notes, whether or not I watch the fight is only loosely connected to the issue of whether it occurs; from that perspective, my individual

17 Andrew McAfee and Erik Brynjolfsson, The Second Machine Age (New York: W. W. Norton \& Company, 2014). 
decision seems mostly relevant to the level of pleasure that $I$ receive. And insofar as utilitarianism is bound to consider all pleasures equally, if I really would get less pleasure from watching football than bull fighting, then I might be morally obligated to watch the fight if I can make no difference to the suffering of the bull. ${ }^{18}$ The non-rival nature of mass entertainment is relevant for the utilitarian not only as passive, isolated consumers, but as potential active opponents, of various practices. When we are deciding, under a utilitarian theory, whether to try to prevent a practice, whether as protestors or as law makers, organisers and television executives, we face the following choices: allow or ban the practice; promote or reject it; protest it, let it happen, or support it. Even if one is doubtful of the efficacy of an individual's decision to stop personally watching the fight, the question of how the practice's end would affect the mass of people is relevant to these questions. If bull fighting is sufficiently popular, it seems irrelevant for a utilitarian from this perspective that there are other forms of entertainment that people can enjoy. The relevant question is whether more pleasure is caused by banning or permitting the practice; by promoting or rejecting it. If sufficient numbers of people get enjoyment, however trivial, from bull fighting, and would on average get less pleasure from other forms of entertainment if it were banned, or simply not promoted, then the utilitarian seems bound to say that it should be permitted and promoted. Even if the pain of the animal outweighs the difference in pleasure for one dissatisfied fan (or would do so, if that fan's refusal to watch could make any difference) - the total balance will be very different for a mass audience because the amount of pain caused to the animal need not change even as the amount of pleasure sacrificed grows significantly. The aggregate of even quite small differences in pleasure between a large group who watch a bull fight, and the same group watching the football, adds up. This is unlike the animal food industry: to please more people with animal food products, more animals have to suffer. So the relationship between the level of animal suffering, and the level of human pleasure, remains somewhat constant. In the case of televised sport, that relationship is entirely untethered.

The focus of the utilitarian view is not on the 'trivial' nature of the pleasures involved in exploiting animals, but on the relative inefficiency to which this triviality contributes. So those who are opposed to granting trivial pleasures any contest with animal lives and fundamental welfare will find themselves in tension with the utilitarian when this link is broken, as it is in cases of mass-televised animal cruelty that also provides mass entertainment. Televised animal cruelty is a potentially very efficient deliverer of pleasure, and so seems to be condoned by utilitarian argument.

An anonymous reviewer notes that this argument ignores the significant distress caused by televised bull-fighting to those who oppose it. This would certainly need to go into a utilitarian calculus. Nonetheless, it does not seem to me to change the overall force of the argument, the central point of which is that the relationship between animal suffering and human pleasure that licenses the utilitarian-vegan conclusion when it comes to meat eating does not exist in the use of animals for entertainment. ${ }^{19}$

18 See also Hud Hudson, 'Collective responsibility and moral vegetarianism', Journal of Social Philosophy 24:2 (1993), pp. 89-104, at p. 94.

19 I would add that although it is an empirical question, it also seems unlikely to me that the effect on distress will be comparable with the effect on pleasure. Many people who would feel distress at animal cruelty would simply avoid watching it or thinking about it. Merely having the opportunity 


\section{The Efficacy Problem}

I suggested in the previous section that although the non-rival nature of televised entertainment makes no difference to the utilitarian morality of bull fighting for the individual, it also seems to be the case that, in the context of televised bull fighting, a fan's decision not to watch it makes only a negative difference to the overall balance of pain and pleasure. This is because the fan will be unhappy (or at least less happy than if he were watching) while the pain of the bull is not eliminated, or even reduced. A similar concern applies to other forms of animal exploitation. My decision not to buy meat saves no animals, because the companies from which I buy my food do not base their policies on any individual's consumer habits.

One potential response to this is a probabilistic one. Even if it is true that no individual decision will change anything, there is a small chance that my decision could be the one that changes a group that is just too small for the industry to notice into one that is just big enough for them to notice. ${ }^{20}$ As Norcross puts it, suppose that:

For each group of 10,000 who give up chicken, a quarter of a million fewer chickens are bred per year [...] if you give up eating chicken, you have only a one in ten thousand chance of making any difference to the lives of chickens, unless it is certain that fewer than 10,000 people will ever give up eating chicken, in which case you have no chance [...] While the chance that your behavior is harmful may be small, the harm that is risked is enormous [...] A one in ten thousand chance of saving 250,000 chickens per year from excruciating lives is morally and mathematically equivalent to the certainty of saving 25 chickens per year. We commonly accept that even small risks of great harms are unacceptable. ${ }^{21}$

Such a response agrees that one's chance of making a difference is small. But it responds by also denying that the difference one would make if one made any difference is merely one's own meat consumption; for the circumstances under which one would make a difference are those in which one tips a balance that contains the decisions of thousands of other people. Given such an assumption, the expected benefit of my giving up meat (that is, the size of benefit multiplied by the likelihood of success) is around the same as if I had personally prevented the deaths of one person's meat consumption.

I will assume for the sake of argument that this is a correct, or near enough correct, description of the meat industry. ${ }^{22}$ It is worth noting, along with Nobis that at least the strand of argument quoted above is not obviously available to utilitarians who base their moral assessment on actual outcomes. ${ }^{23}$ After all, even if I cannot know whether the chicken I am eating is the 'threshold' chicken, my act is only wrong if it actually is the threshold. It is not wrong to take risks, for an actual-outcome utilitarian

to be distressed is not necessarily distressing. Those who would enjoy the spectacle, on the other hand, are more likely to actually be affected by its availability because they are more likely to actually watch.

20 E.g. Singer, 'Utilitarianism and Vegetarianism'; Matheney, 'Expected Utility, Contributory Causation, and Vegetarianism'.

21 Norcross, 'Puppies, Pigs and People', p. 233.

22 For some dissent on the issue of thresholds, see Raymond Frey, Rights, Killing and Suffering: Moral Vegetarianism and Applied Ethics (Oxford: Basil Blackwell, 1983), p. 214.

23 Nathan Nobis, 'Vegetarianism and Virtue: Does Consequentialism Demand too Little?', Social Theory and Practice 28:1 (2002), pp. 135-156, at pp. 142-143, n20. 
(aside from possible distress one might cause to others or oneself in doing so); I would merely be taking a risk of doing something wrong. So this argument seems to rely on a form of utilitarianism that says that one ought to do what one reasonably expects to have the best outcomes. Norcross offers an additional thought, however, that may be available to actualist utilitarians: even if I do not in fact tip any particular balance, my decision will reduce the amount of time before that balance is tipped by someone else. ${ }^{24}$ It seems questionable whether this outcome outweighs the pleasure gained from eating chicken. But I will assume for the sake of argument that we are considering the more secure appeal to expected benefit.

There is a further problem with this argument, not raised by its other critics. As quoted above, Norcross seems to suggest that the probabilistic utilitarian view falls in line with common sense, since 'We commonly accept that even small risks of great harms are unacceptable.' If commonly is taken to mean 'often', then this is certainly true, and Norcross provides several examples of objectionable negligence where the risk is unlikely, but severe: failing to secure a child in their car seat; drinking heavily during pregnancy; corporate negligence in airline safety. But as well as all being cases of unlikely but potentially high-cost risks, these examples all have other things in common with the case of the meat industry; and cases that lack these features while maintaining the feature of the small risk of a great harm are not so commonly viewed as unacceptable. Finally, these features are not ones that a utilitarian view can make direct use of. So it is misleading to imply that utilitarianism falls in line with 'common' acceptance.

The first feature is that all of these risks are not consented to; indeed, aside from the final example they are not such that their potential victims can consent: children, animals and the unborn cannot give consent for harms in any meaningful way. The second is that, at least as Norcross presents them, they are examples where the intended risks and benefits are distributed across different people, and where the intended benefits are accrued by those who take the risky decision, but who do not suffer the risk. In a typical case where an airline fails to spend money on standard safety measures, for instance, the passengers are unlikely to be consulted, and hence cannot give their consent, and are also unlikely to be the intended beneficiaries of such corner cutting. Someone who drinks heavily during pregnancy imposes risks on her child, but the benefits of drinking are enjoyed only by her. Both of these features apply to the animal industry: animals cannot give their consent to being killed for our pleasure, and presumably would not, if they could. And even if animals do incur some benefits while being reared for meat or other products (e.g. veterinary care), the aims of the industry are entirely focused on benefits for producers and consumers.

One might think that the 'Replaceability Argument' speaks against this latter claim. ${ }^{25}$ This argument says that from a utilitarian perspective, it would be permissible to rear and kill animals so long as they had lives that were worth living, had no or only weak future preferences that killing them would thwart, and were replaced by equally happy, or happier, animals that would not have been brought into existence under a different system. This would be better than a vegan world because such a world would never bring the vast majority of animals into existence, depriving them of happy lives. But whatever the pragmatic plausibility of such a view, even if it would be better for the

${ }^{24}$ Norcross, 'Puppies, Pigs and People', p. 233.

25 E.g. Singer, Practical Ethics, p. 121. 
animal to live and die than not to live at all, this does not show that a creature that actually lived under such a system would rationally consent to die in order to perpetuate it. And it does not show that such a system has benefits to the animal as an aim when it rears them.

Unlike the problem of efficiency, this argument does not tell utilitarians to support animal cruelty in certain cases. Rather, the issue is that the argument makes no distinction between the kind of probabilistic risk to others that one takes when one buys meat, and other kinds of risk that are far less obviously immoral. In other words, the issue is that this argument, if taken at face value, condemns too much. Imagine that Norcross' airline could take out oxygen masks, life jackets and emergency exits as he imagines, but that it informs potential passengers of its decision, and passes (some of) the savings onto them in the form of cheaper flights. Similarly, lowering the speed limit for drivers in Formula 1 races might have a significant impact on the risk of fatality; but drivers might consent to the risks of higher limits on the grounds that it would compromise the sport.

If drivers consent to driving at current speeds, or airline passengers willingly consent to additional safety risks, Norcross' argument seems to suggest that this is just as wrong, and just as obviously wrong, as it is for a parent to fail to strap in their child in a short car journey, or for any of us to purchase animal products. One cannot support the probabilistic argument as being in line with common sense morality, as Norcross does, simply by pointing to some cases where unlikely but serious risks are not tolerated. This is because there are other similarities between these cases; and, crucially, these similarities make use of concepts to which utilitarians cannot directly help themselves in moral argument. I do not claim that it is obvious that we should permit voluntary deregulation of airline safety, or oppose a speed limit in Formula 1; rather, the morality of those decisions, even given equivalent numbers, is not the same as the question of whether we should risk being the person who could, but did not, make a difference of 10,000 chicken deaths to the yearly toll of the meat industry. In the former cases there is the potential for consent; in the latter there is not. ${ }^{26}$ This is further supported by the thought that a meat industry that did give animals a life worth living, and to which the likely alternative was that those animals would never exist, should find support among utilitarians. But most everyday vegans would not support it even on those terms.

This is not to say that utilitarians have no further response. Indeed, they do have a persuasive response, and one to which Norcross briefly alludes. The problem, as I will argue in the fourth section, is that the radical nature of this response contributes to a further problem with the utilitarian view. The argument I have in mind is hinted at, briefly, by Norcross when he says, 'Furthermore, many people who become vegetarians influence others to become vegetarian, who in turn influence others, and so on'. ${ }^{27}$ One's options when it comes to animal products are not simply to eat or abstain. There are a great many activists who not only refuse to eat animal products themselves, but put a great deal of money and effort into persuading others to follow them. Whatever they say about the expected benefit of giving up animal products, utilitarians should support

26 See also Sven Ove Hansson, 'Risk and Ethics: Three Approaches', in Risk: Philosophical Perspectives, edited by Tim Lewens (Abingdon: Routledge, 2007), pp. 21-35.

27 Norcross, 'Puppies, Pigs and People', p. 233. 
active as well as passive responses to the animal industry: 28 certainly persuasion, certainly political organisation, and perhaps even criminal sabotage of the meat industry, such as rescue of animals marked for slaughter, although this will depend on how various actions affect animals currently trapped inside the industry, and how well these animals can be cared for. I will now explain why such a position, compelling as it is, runs into some problems as a utilitarian response.

\section{The Other Pleasures Problem}

I have suggested that one utilitarian response to the efficacy problem - whatever one's stance on the expected benefit issue - is to admit that we are morally obligated to do more than passively refrain from certain practices; at the least, we ought to persuade others to do so as well. What this means, however, is that a utilitarian cannot simply factor in their own feelings when comparing them against the suffering of animals; the utilitarian response to animal suffering must be public and active, not private and passive. And this may lead to a further wrong-making feature of the superficially obvious utilitarian support of veganism. My focus in this section is on kinds of pleasure other than those of taste that eating animal products gives to many people. My argument bears significant debt to an argument outlined by Coleman about the permissibility of slavery under utilitarianism. To reiterate: I do not intend for there to be any analogy between the case of racialized slavery that Eoleman discusses, and the case of animal slaughter, other than the broad form of the argument. I will briefly outline Coleman's case, before explaining how I think it transfers to the case of non-human animals.

Eoleman considers, among various arguments for the wrongness of slavery, the apparently common assumption that utilitarianism will clearly oppose slavery on the grounds that the pains suffered by slaves will obviously outweigh any gains to slaveholders. Coleman responds that in the specific case of racialized slavery - that is, black slaves held captive by whites, such as occurred in antebellum America - this ignores the aggregate effects of three further benefits: 'Schadenfreude, security and status' ${ }^{29}$ Schadenfreude, because some white slavers actively enjoyed causing misery to their slaves; security, because the control of considerable labour power brought a sense of security to slavers; and status, because racialized slavery created superior social categories, including the category of 'white', which benefitted even those who were not slavers. These categories also apply, to differing degrees, to the utilitarian support of veganism.

Consider once more Singer's claim that the pleasures involved in meat-eating are trivial compared with the suffering of animals. As we have already seen, Regan raises a significant problem with this view: even if the pleasures directly associated with eating meat are easily outweighed, the meat industry supports a great many employees, and their families. This may be classed as a pleasure of security; the existence of a successful meat industry provides at least some of its economic agents with financial stability, and

28 Indeed, Frey, in Rights, Killing and Suffering, argues throughout that the correct response is to actively protest factory farming while continuing to eat meat, on the grounds that the former can make a difference, and the latter cannot

29 Coleman, What is wrong with [R.M. Hare's argument against] slavery', pp. 6-7 
hence a feeling of security. While a single person's decision to abstain from meat will not bring the entire industry crashing down, we can reorient Norcross' probabilistic argument to this issue. Firms' hiring practices are related to their profits; if every person who becomes vegan brings us closer to a tipping point where fewer animals are bred, then they must also bring companies who make those reductions closer to the point where they reduce the number of employees they have. Perhaps those employees will get other jobs, but perhaps they will not; even if they will, threats to the animal industry will increase the feeling of insecurity among the industry's workforce.

Turning briefly to Schadenfreude, there are surely some people in charge of animals who get pleasure from mistreating them. While this is unlikely to be motivated by hatred - as may have been the case in the examples Eoleman cites - a utilitarian cannot simply discount these pleasures. Although it is perhaps reasonable to assume that these will not outweigh the displeasure experienced by the mistreated animals by themselves, they still contribute to the overall hedonistic benefit of the industry; and it would be significantly harder, though by no means impossible, for a sadist who has found their niche in the industry to get those pleasures without such an outlet.

Finally, there is the issue of status. Just as racialized slavery can benefit those whites who did not hold slaves by placing them in one or more socially superior classes, the animal industry may psychologically benefit many humans by placing them into a category - enabled only by its contrast with non-human animals - of creatures that cannot legitimately be treated the way we treat animals. This status may benefit those who oppose animal exploitation, and even those who are theoretically opposed to the idea of human superiority. Our language is filled with examples of derogatory comparisons to animals, including examples where cruel treatment of animals is justified in the act of denouncing such treatment when applied to humans: 'This company is a disgrace; they crowded us onto the train like cattle'; 'I treat my dog better than that'; and so on.

A vocal opposition to animal exploitation that made use of the idea that animals are our moral equals challenges our superiority, and unsettles reliably reassuring categories into which we place ourselves. Such arguments will, and already do, cause significant anger and distress. Many supporters of animal rights experience upset and anger from others simply for explaining their views on animal equality, even when those views are actively sought out; if, as the previous section suggested, utilitarian arguments imply that a passive refusal to eat animal products is not enough, active protest against the animal product industry seems likely to cause even more upset and anger, even if it is also a more effective way of convincing some people than passive refusal alone. In addition, it is important to note, in contrast with many expressions of human equality, that animals cannot benefit psychologically from the mere fact that others are fighting their corner, and expressing their right to equal treatment.

This is not the only way that animal cruelty confers status. I briefly mentioned in the second section the idea that animal products may not be automatically replaceable in the way one might assume, because the fact that something is an animal product is itself relevant to the pleasure. In at least some such cases, this is a question of status. The fact that one's shoe, or bag, or jacket is made of real leather affords you a level of status that wearing a fake will not. The fact that one is hunting a real fox, rather than simply riding around with hounds and horses, may be integral for some hunters to the enjoyment of the practice. Thus, the exploitation of animals provides ample opportunities for people to experience the pleasures of status, and of 'quality'. 
Utilitarians, among others, may regard these reactions as irrational or selfish. But, at least according to the classical utilitarianism of Mill, Bentham and Singer, pleasures and pains are to be counted according to their intrinsic value or disvalue; the fact that they are irrational or selfish is not a reason in itself to discount them from our calculation..$^{30}$ The sheer scale of animal suffering in the current industry may make it seem fairly unlikely that, even given these additional considerations, human pleasure will outweigh that suffering. I am not sure it is such an easy matter to estimate; but it remains the case that a more refined version of animal exploitation might pass such a test. So long as animals are widely regarded as eligible for exploitation and cruel treatment in a way that humans are not, the psychological benefits of animal oppression have scope to continue. This seems to me to be another area in which a majority of animal welfare supporters ought to part from utilitarianism.

\section{Conclusion}

I have considered three ways that utilitarian theory seems to lead us away from various practices that are typical among supporters of animal rights and welfare. First, utilitarianism opposes animal exploitation, when it does, for the only reason that it opposes anything: because it is a comparatively inefficient way of getting pleasure over pain. But there are many examples of animal cruelty to which this apparent inefficiency does not obviously apply. Second, utilitarians face the problem that our individual actions seem to make little or no difference to animal suffering, and a standard utilitarian answer to this seems to rely on moral difference-making features of decision-making such as consent to which utilitarian theory is not welcome. An alternative utilitarian response - that we ought to do more than merely abstaining - is more persuasive. But it exacerbates a third problem with the connection between utilitarianism and everyday veganism, which is that the benefits many humans get from the use of animals extend beyond the immediate pleasure of that usage.

None of this is likely to persuade a committed utilitarian to give up their theory, since committed utilitarians are not typically persuaded to give up their comprehensive theory by first-order moral claims. What I hope to have done in this essay is raise further doubts, beyond those already raised by others, about the obviousness of the connection between utilitarianism and ending animal exploitation. For those who reason morally from the 'bottom up', a commitment to animal welfare should not lend utilitarianism much support as a normative theory; from the perspective of everyday vegans, utilitarianism gets plenty wrong. This is not to diminish the extent to which utilitarian writers have pushed boundaries when it comes to animal welfare; none of what I have said denies that utilitarian arguments comprehensively denounce our current practices, and raise animals to a level of moral concern in an admirably straightforward way. But it

30 Fred Feldman, Pleasure and the Good Life: Concerning the Nature, Varieties and Plausibility of Hedonism (Oxford: Oxford University Press, 2004), at pp. 117-123; 192-197 outlines various adjustments to simple hedonism that weight the value of pleasures and pains according to factors such as how much their recipients deserve them, or how appropriate the relevant attitude is. A utilitarianism that made use of this kind of view might be able to discount the moral worth of selfish or irrational pleasures, though this is still no guarantee that the balance would come out against some form of animal exploitation. 
is also true, and worth remembering, that many of the persuasive arguments that utilitarians like Singer, Bentham and Norcross offer do not require a commitment to utilitarianism to be persuasive. Insofar as one is persuaded by these arguments, one ought not be a utilitarian.

Ben Davies, Bloomsburg University of Pennsylvania davies.bt@hotmail.co.uk

\section{Bibliography}

Bentham, Jeremy. An Introduction to the Principles of Morals and Legislation. Oxford: Clarendon Press, [1789] 1907.

Coleman, Nathaniel. 'What Is Wrong with [R.M. Hare's Argument against] Slavery', online at: https://www.academia.edu/2761414/What_is_wrong_with_R._M._Hares_ arguments_against_slavery. Unpublished (accessed 2016-05-26).

Davis, Steven. 'The Least Harm Principle May Require that Humans Consume a Diet Containing Large Herbivores, Not a Vegan Diet', Journal of Agricultural and Environmental Ethics 16:4 (2003), pp. 387-394.

De Lazari-Radek, Katarzyna, and Peter Singer. The Point of View of the Universe: Sidgwick and Contemporary Ethics. Oxford: Oxford University Press, 2014.

Dick, Philip K. Do Androids Dream of Electric Sheep? Orion Books: London, [1968] 1999.

Donaldson, Sue, and Will Kymlicka. Zoopolis: A Political Theory of Animal Rights. Oxford: Oxford University Press, 2011.

Donovan, Josephine. 'Animal Rights and Feminist Theory', Signs 15:2 (1990), pp. 350-375.

Feldman, Fred. Pleasure and the Good Life: Concerning the Nature, Varieties and Plausibility of Hedonism, Oxford: Oxford University Press, 2004.

Frey, Raymond. Rights, Killing and Suffering: Moral Vegetarianism and Applied Ethics. Oxford: Basil Blackwell, 1983.

Hansson, Sven Ove. 'Risk and Ethics: Three Approaches', in Risk: Philosophical Perspectives, edited by Tim Lewens. Abingdon: Routledge, 2007, pp. 21-35.

Gender, Race and Philosophy: The Blog, 'How Philosophy Was "Whitewashed", interview with Dr Nathaniel Coleman' (August 24th, 2015), online at sgrp.typepad.com/sgrp/2015/08/how-philosophy-was-whitewashed-an-interviewwith-dr-nathaniel-adam-tobias-coleman-by-aaron-salzer-of-scienceorfat-t.html (accessed 2016-05-25).

Hudson, Hud. 'Collective Responsibility and Moral Vegetarianism', Journal of Social Philosophy 24:2 (1993), pp. 89-104.

Matheny, Gaverick. 'Expected Utility, Contributory Causation, and Vegetarianism', Journal of Applied Philosophy 19:3 (2002), pp. 293-297.

Matheny, Gaverick. 'Least Harm: A Defense of Vegetarianism from Steven Davis's Omnivorous Proposal', Journal of Agricultural and Environmental Ethics 16:5 (2003), pp. 505-511.

Matheny, Gaverick. 'Utilitarianism and Animals', in In Defense of Animals: The Second Wave, edited by Peter Singer. Oxford: Blackwell, 2005, pp. 13-26.

McAfee, Andrew, and Erik Brynjolfsson. The Second Machine Age. New York: W. W. Norton \& Company, 2014. 
McMahan, Jeff. 'The Meat Eaters', The New York Times (September 19th, 2010), online at http://opinionator.blogs.nytimes.com/2010/09/19/the-meat-eaters (accessed 201605-25).

Mill, John Stewart. 'Whewell on Moral Philosophy', in The Collected Works of John Stuart Mill, edited by John M. Robson. London: Routledge and Kegan Paul, [1852] 1963-1991, pp. 165-202.

Nobis, Nathan. 'Vegetarianism and Virtue: Does Consequentialism Demand too Little?', Social Theory and Practice 28:1 (2002), pp. 135-156.

Norcross, Alastair. 'Puppies, Pigs and People', Philosophical Perspectives 18:1 (2004), pp. 229-245.

Regan, Tom. 'Utilitarianism, Vegetarianism, and Animal Rights', Philosophy \& Public Affairs 9:4 (1980), pp. 305-324.

Regan, Tom. The Case for Animal Rights, $2^{\text {nd }}$ Edition. California: University of California Press, [1983] 2004.

Saul, Heather. 'Hatched, Discarded and Gassed: What Happens to Male Chicks in the $\mathrm{UK}^{\prime}$, The Independent (March 5 $\left.{ }^{\text {th }}, 2015\right)$, online at http://www.independent.co.uk/lifestyle/food-and-drink/hatched-discarded-gassed-what-happens-to-male-chicks-inthe-uk-10088509.html (accessed 2016-05-25).

Sidgwick, Henry. The Methods of Ethics, $7^{\text {th }}$ edition. London: MacMillan, [1874] 1907.

Singer, Peter. 'The Fable of the Fox and the Unliberated Animals', Ethics 88:2 (1978), pp. 119-125.

Singer, Peter. 'Utilitarianism and Vegetarianism', Philosophy and Public Affairs 9:4 (1980), pp. 325-337.

Singer, Peter. Animal Liberation, 2nd Edition. London: Cape, [1975] 1990.

Singer, Peter. Practical Ethics, 3rd Edition. Cambridge: Cambridge University Press, [1979] 2011. 